\title{
PENINGKATAN KUALITAS AIR LIMBAH TEROLAH \\ INDUSTRI PENYAMAKAH KULIT MENGGUNAKAN TAMAN \\ TANAMAN AIR DENGAN TUMBUHAN BAMBU AIR
}

\section{IMPROVEMENT OF TREATED TANNERY WASTEWATER USING CONSTRUCTED WETLAND SYSTEM VEGETATED WITH Equisetum hyemale}

\author{
Prayitno*, Muhammad Sholeh \\ Balai Besar Kulit, Karet, dan Plastik, Yogyakarta \\ *E-mail: prayitno_bbkkp@yahoo.com
}

Diterima: 20 Februari 2014 Direvisi: 16 Mei 2014 Disetujui: 19 Mei 2014

\begin{abstract}
A research of constructed wetland system vegetated with Equisetum hyemale for treating of treated tannery wastewater have been conducted. The constructed wetland was $3 \mathrm{~m}$ long, $1 \mathrm{~m}$ wide, and $1 \mathrm{~m}$ deep or equal with volume of $3 \mathrm{~m}^{3}$. The construction of wetland consisted of 4 main layers (from the bottom to the top): $0.3 \mathrm{~m}$ of rock; $0.3 \mathrm{~m}$ of gravel; $0.1 \mathrm{~m}$ of black sugar-palm fiber; and $0.3 \mathrm{~m}$ of sand. The wetland was operated with subsurface flow system (SSF). The detention time was varied at 3.125; 2.083; and 1.563 days. The result showed that the optimum removal were $60.60 \%$ for COD with detention time of 3.125 days, $60.17 \%$ for BOD with detention time of 2.083 days, $93.76 \%$ for TSS with detention time of 3.125 days, $89.02 \%$ for $S$ with detention time of 3.125 days and $96.89 \%$ for total chrome wth detention time of 2.083 days.
\end{abstract}

Keyword: treated tannery wastewater, Equisetum hyemale, detention time

\section{ABSTRAK}

Telah dilakukan penelitian taman tanaman air (TTA) dengan tanaman bambu air untuk mengolah limbah cair terolah industri penyamakan kulit. Konstruksi TTA berukuran panjang $3 \mathrm{~m}$, lebar 1 $\mathrm{m}$, dan dalam $1 \mathrm{~m}$, atau sama dengan volume $3 \mathrm{~m}^{3}$. Media terdiri atas empat lapisan mulai dari bawah adalah koral $0,3 \mathrm{~m}$, kerikil $0,3 \mathrm{~m}$, ijuk $0,1 \mathrm{~m}$, dan lapisan paling atas adalah pasir 0,3 m. TTA dioperasikan dengan sistem aliran subsurface (SSF). Waktu tinggal divariasi berturut-turut pada 3,$125 ; 2,083$; dan 1,563 hari. Hasil penelitian menunjukan efektivitas penurunan COD sebesar $60,60 \%$ dengan waktu tinggal 3,125 hari, penurunan BOD sebesar $60,17 \%$ dengan waktu tinggal 2,083 hari, penurunan TSS sebesar 93,76\% dengan waktu tinggal 3,125 hari, penurunan S sebesar $89,02 \%$ dengan waktu tinggal 3,125 hari dan penurunan krom sebesar 96,89\% dengan waktu tinggal 2,083 hari.

Kata kunci: air limbah penyamakan terolah, Bambu air, waktu tinggal

\section{PENDAHULUAN}

Industri penyamakan kulit sangat potensial menghasilkanlimbahdanmencemarilingkungan apabila tidak dilakukan upaya penanganan limbahnya. Air limbah yang dihasilkan untuk memproses satu ton kulit mentah sebesar 40-50 $\mathrm{m}^{3}$ (Shreesadh et al., 2013). Dalam penanganan limbah cair industri kulit sering dijumpai adanya masalah di lapangan yang terkait dengan efluent yang keluar dari unit pengolah limbah. Masalah tersebut meliputi terjadinya kelebihan kapasitas influent karena desain yang kurang tepat dan adanya kenaikan produksi pada saat bahan baku kulit mentah melimpah disisi lain 
produksi kurang dikarenakan kekurangan bahan baku (Calheiros et al, 2007). Hal tersebut dapat menyebabkan terjadinya shock loading yang mengakibatkan kerja biomas dalam memecah limbah akan terganggu aktivitasnya, sehingga effluent limbah terolah juga akan sangat bervariasi. Untuk mendapatkan air limbah yang memenuhi baku mutu dan seragam, perlu pengolahan tersier lebih lanjut.

Sejak pertengahan tahun 1990, TTA yang rendah konsumsi energinya telah meningkat penggunaannya untuk mengolah air limbah (Lee et al., 2009). TTA dapat digunakan untuk penanganan limbah primer, sekunder, maupun tersier. Jenis limbah cair yang dapat diolah dapat berasal dari limbah cair rumah tangga (Afrous et al., 2010; Chong et al., 2009), pertanian (Sarafraz et al., 2009), landfill leachate (Yalcuk and Ugurlu, 2009), dan industri (Calheiros et al., 2009). Penggunaan wetland untuk penanganan limbah industri perlu kehati-hatian dikarenakan komposisi limbah industri yang sangat bervariasi dan juga secara kuantitas kadar pengotornya biasanya sangat tinggi, sehingga untuk penanganan limbah industri wetland sebaiknya digunakan untuk penanganan limbah tersier, yang kosentrasi limbahnya sudah rendah.

Pengolahan air limbah menggunakan teknologi wetland cocok untuk mengolah limbah dengan beban organik yang rendah pada pengolahan sekunder atau tersier (Vymazal and Kröpfelová, 2009). Pengolahan limbah dengan menggunakan TTA tipe SSF memanfaatkan simbiosis mikroorganisme dalam tanah dengan akar tumbuh-tumbuhan yang mengeluarkan oksigen. Air tidak menggenang diatas media tanam tetapi mengalir dibawah media sehingga memiliki berbagai keuntungan. Salah satu keuntungannya adalah tumbuhan yang dapat beradaptasi pada media tersebut bervariasi, sehingga dapat digunakan tanaman estetika, salah satunya adalah jenis tanaman bambu air (Equisetum hyemale).

Untuk mengetahui efektifitas bambu air sebagai tanaman yang digunakan pada TTA dengan sistem aliran subsurface dalam meningkatkan kualitas limbah cair terolah dari unit pengolah limbah cair penyamakan kulit, perlu dilakukan penelitian dengan memvariasi waktu tinggal.

\section{BAHAN DAN METODE Bahan Penelitian}

Bahan terdiri atas tanaman bambu air (Equisetum hyemale), air limbah effluent dari UPAL Laboratorium Penyamakan Kulit Balai Besar Kulit, Karet, dan Plastik di Sitimulyo, Yogyakarta.

\section{Peralatan Penelitian}

Peralatan penelitian terdiri atas unit TTA, dimensi (panjang $\mathrm{x}$ lebar $\mathrm{x}$ dalam) adalah (3 $\mathrm{x} 1 \mathrm{x}$ 1) $\mathrm{m}^{3}$ atau identik dengan volume $3 \mathrm{~m}^{3}$. Media pengisi taman tanaman air terdiri atas lapisan paling bawah koral diameter $\pm 10 \mathrm{~cm}$ dengan ketebalan $0,3 \mathrm{~m}$, lapisan kedua berupa kerikil dengan diameter $\pm 3 \mathrm{~cm}$ ketebalan $0,3 \mathrm{~m}$, lapisan ketiga berupa ijuk dengan ketebalan \pm 10 $\mathrm{cm}$ dan lapisan paling atas berupa pasir dengan ketebalan $0,3 \mathrm{~m}$, sistem aliran menggunakan sistem upflow. Gambar wetland seperti terlihat pada Gambar 1. Peralatan pendukung yaitu gelas ukur $1000 \mathrm{ml}$, stopwatch, dan alat pengambil sampel.

\section{Metode Penelitian}

Penelitian ini dilakukan dengan membangun TTA dengan tanaman bambu air (Equisetum hyemale) terlihat pada Gambar 2. Wetland yang telah siap, sebelum dilakukan penanaman tumbuhan air dilakukan pembersihan dengan mengalirkan air sumur selama 2 hari sehingga air yang keluar dari outlet jernih, kemudian dilakukan penanaman bambu air dengan jarak tanam $30 \mathrm{~cm}$. Tanaman dibiarkan tumbuh dengan air bersih mengalir sampai 2 minggu (tanaman sudah kelihatan berkembang). Kemudian dilakukan feeding dengan limbah terolah. Feeding dilakukan pertama dengan waktu tinggal yang pendek dengan debit lebih besar kemudian waktu tinggal diperpanjang dengan menurunkankan debit masuk. Variabel yang digunakan adalah waktu tinggal dengan variasi 3,125;2,083; dan 1,563 hari. Terhadap penurunan kadar pencemar masuk (inlet) dan keluar (outlet) dari unit taman tanaman air digunakan untuk perhitungan efektifitas pengurangan bahan pencemar. Parameter yang diuji yaitu COD, BOD, TSS, sulfida, dan krom total. Pengujian mengacu pada Standard Nasional Indonesia.

Untuk menghitung konstanta kecepatan 


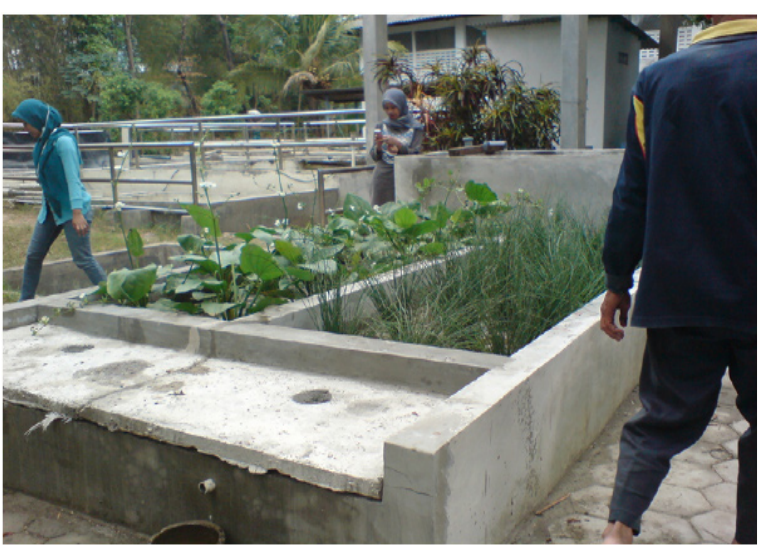

Gambar 1. Taman tanaman air dengan tanaman bambu air

reaksi digunakan persamaan dari USEPA (1998) dengan asumsi reaksi kinetik terjadi adalah reaksi order satu maka :

$\mathrm{C}_{\mathrm{e}}=\mathrm{C}_{\mathrm{o}} \mathrm{e}^{- \text {Ks.t }}$

$\mathrm{C}_{\mathrm{e}}$ adalah konsentrasi efluent $(\mathrm{mg} / \mathrm{l}), \mathrm{C}_{\mathrm{o}}$ adalah konsentrasi influent $(\mathrm{mg} / \mathrm{l}), \mathrm{K}_{\mathrm{s}}$ adalah konstanta kecepatan reaksi suhu percobaan $\left(\mathrm{d}^{-1}\right)$, dan $\mathrm{t}$ adalah waktu tinggal limbah (d).

Persamaan (1) dimanipulasi membentuk persamaan linier sebagai berikut.

$$
\begin{aligned}
& \mathrm{C}_{\mathrm{e}} / \mathrm{C}_{\mathrm{o}}=\mathrm{e}^{-\mathrm{Ks.t}} \\
& \ln \mathrm{C}_{\mathrm{e}} / \mathrm{C}_{\mathrm{o}}=-\mathrm{Ks} . \mathrm{t}
\end{aligned}
$$

\section{HASIL DAN PEMBAHASAN Penurunan COD}

Dari Gambar 3 terlihat bahwa efektifitas penurunan COD naik seiring dengan naiknya waktu tinggal. Untuk waktu tinggal berturutturut 1,$563 ; 2,083$ dan 3,125 hari, efektifitas penurunan COD berturut-turut 17,89; 47,27; dan $60,60 \%$. Dari keadaan tersebut, waktu tinggal sangat mempengaruhi kecepatan pengurangan beban COD. Penurunan COD maksimum diperoleh sebesar $60,60 \%$ dengan waktu tinggal 3,125 hari. Dari penelitian Debing et al. (2010) dengan wetland menggunakan tanaman Typha angustata $s p$. diperoleh efektifitas penurunan COD sebesar $71.20 \%$ untuk waktu tinggal 2,55 hari, sedangkan Karunaratne (2011) dalam penelitiannya menggunakan wetland dengan tanaman Typha latifolia sp untuk mengolah grey water diperoleh waktu tinggal optimum untuk penurunan COD adalah 2,2291 hari dengan kandungan COD awal $250 \mathrm{mg} / \mathrm{l}$.

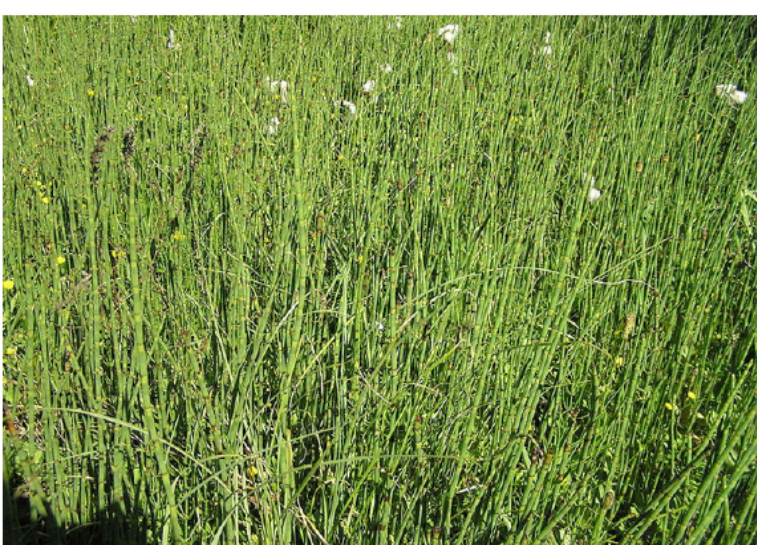

Gambar 2: Bambu air (Equisetum heymale)

Penurunan kadar COD yang belum optimal pada perlakuan ini diduga disebabkan oleh pengurangan COD pada sistem wetland melalui mekanisme: filtrasi, sedimentasi dan juga oleh aktivitas mikroorganisme dalam media maupun akar tanaman (Ahmad, 2009), sehingga waktu tinggal masih belum memberi kesempatan sedimentasi maupun pemecahan yang cukup oleh mikroorganisme. Penelitian Borkar and Mahatme (2011) menggunakan limbah rumah tangga dengan waktu tinggal 3 hari mendapatkan penurunan COD sebesar 35\%, sedangkan untuk waktu tinggal 7 hari sebesar $66 \%$. Lain halnya dengan Calherios (2010) yang menyatakan bahwa dengan waktu tinggal 2 hari penurunan COD sebesar $62 \%$, sedangkan untuk waktu tinggal 5 hari sebesar $79 \%$.

\section{Penurunan BOD}

Mekanisme pengurangan BOD pada unit wetland terjadi dengan cara pemecahan oleh

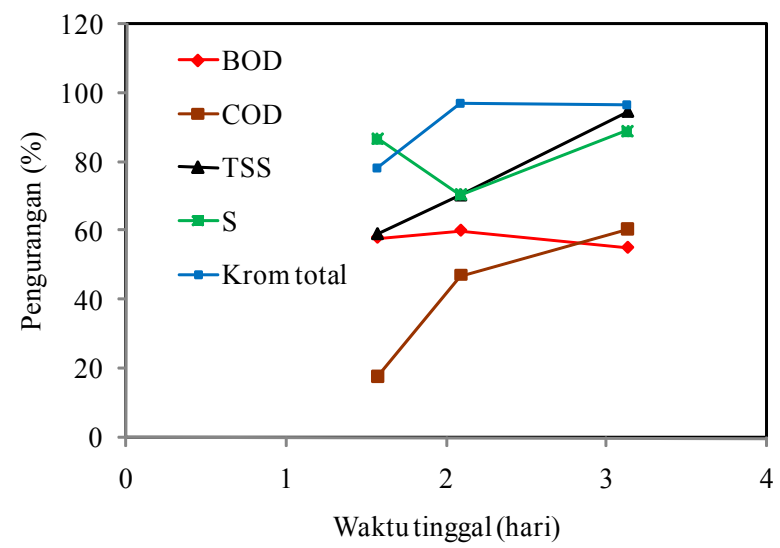

Gambar 3. Pengaruh waktu tinggal terhadap penurunan konsentrasi polutan . 
mikroorganisme, baik yang melekat pada akar tumbuh-tumbuhan maupun dalam media. Selain itu juga simbiosis mikroorganisme dengan akar tanaman yang menyediakan oksigen. Karena jumlah mikroorganisme baik dalam akar maupun dalam media berkorelasi positif dengan waktu tumbuh tanaman, efektifitas pengurangan BOD juga akan meningkat seiring dengan lamanya waktu pertumbuhan tanaman. Gambar 3 menunjukan bertambahnya waktu tinggal akan meningkatkan efektifitas pengurangan BOD, dengan waktu tinggal 1,563 hari terjadi penurunan $58,12 \%$ dengan waktu tinggal 2,083 hari terjadi penurunan $60,17 \%$. Namun, pada penggunaan waktu tinggal 3,125 hari justru terjadi pengurangan penurunan BOD menjadi $55,18 \%$. Hal tersebut kemungkinan diduga karena bertambahnya waktu tinggal akan mengurangi BOD loading sehingga kemungkinan terjadi shock loading, yaitu makanan yang ada tidak sebanding dengan kebutuhan biomas pendegradasi limbah, sehingga kebutuhan akan makanan diambil dari biomas yang ada. Berdasarkan penelitian Calheiros et al. (2009), dengan waktu tinggal 2 hari terjadi penurunan BOD sebesar $51 \%$ sedangkan dengan waktu tinggal 5 hari penurunan sebesar $68 \%$ sehingga hampir menyamai hasil penelitian.

\section{Pengurangan S, TSS, dan logam krom}

Mekanisme penghilangan sulfida belum jelas di dalam unit wetland. Diduga sulfida dioksidasi untuk menjadi sulfat kemudian dilarutkan dalam air dan dilakukan pembuangan. Untuk logam berat krom kemungkinan diserap oleh akar tumbuhan dan juga diendapkan dalam media, sedangkan TSS melalui sedimentasi dan filtrasi maupun absorpsi baik oleh tanaman maupunoleh media. Meningkatnya waktu tinggal tidak berpengaruh nyata pada peningkatan pengurangan sulfida seperti disajikan pada Gambar 3, dengan waktu tinggal 1,563 hari terjadi pengurangan sulfida $86,67 \%$ dengan waktu tinggal 2,083 hari justru terjadi penurunan menjadi $70,52 \%$ dan dengan waktu tinggal 3,125 hari terjadi kenaikan dalam penurunan kadar sulfida menjadi $89,02 \%$. Penurunan pada waktu tinggal 2,083 hari kemungkinan disebabkan oleh faktor luar termasuk cuaca yang mempengaruhi waktu penguapan sulfida dan juga keasaman dari larutan influent. Pada kondisi asam, sulfida akan sangat mudah lepas dan terjadi gas hidrogen sulfida.

Terjadi kenaikan pengurangan total suspended solid (TSS) yang cukup signifikan dengan bertambahanya waktu tinggal berturutturut dengan waktu tinggal 1,$563 ; 2,083$ dan 3,125 hari sebesar 59,13; 70,37 dan 94,64\%. Hal tersebut karena peningkatan waktu tinggal akan meningkatkan penyerapan dan pengendapan oleh aktifitas tanaman maupun mikrobia dalam media. Hasil penelitian dari Calheiros et al. (2009) menunjukkan bahwa dengan waktu tinggal 2 hari TSS mengalami penurunan sebesar 93\% sedangkan dengan waktu tinggal 5 hari mengalami penurunan kemampuan menyerap TSS menjadi sebesar $88 \%$.

Akar tanaman juga mempunyai kemampuan untuk menyerap logam-logam berat seperti krom. Meningkatnya waktu tinggal limbah yang diolah akan meningkatkan kemampuan penyerapan logam krom oleh akar tanaman, logam krom hampir terserap sempurna dengan waktu tinggal 2,083 hari, kenaikan waktu tinggal tidak meningkatkan penyerapan krom, seperti disajikan pada Gambar 3, dengan waktu tinggal 1,563 hari logam krom terserap sebanyak 78,12\% sedangkan untuk waktu tinggal 2,083 dan 3,125 hari hampir tidak ada perbedaan yaitu 96,89 dan $96,44 \%$. Hal tersebut diduga karena terjadi kejenuhan dalam akar tanaman. Pengurangan logam krom juga dapat disebabkan oleh adanya adsorpsi oleh biomas yang melekat pada media, dimana media juga dapat sebagai tempat tumbuh (attached growth) dari biomas. Penelitian dari Calheiros et al. (2007) menunjukkan bahwa penurunan kadar krom mencapai 94,12\%.

\section{Kinetika Reaksi}

Untuk dasar desain suatu wetland dapat digunakan persamaan yang diberikan oleh USEPA menggunakan persamaan (3). Hasil yang diperoleh untuk BOD dan COD terlihat pada Gambar 4.

Dari Gambar 4, terlihat bahwa persamaan (3) dapat diaplikasikan untuk COD dengan nilai $\mathrm{R}^{2}=0,880$, tetapi tidak sesuai untuk BOD. Konstanta kecepatan reaksi yang diperoleh yaitu $\mathrm{K}_{\mathrm{s}}=0,275 /$ hari. Dari penelitian Karunaratne (2011) penggunaan wetland untuk mengolah 


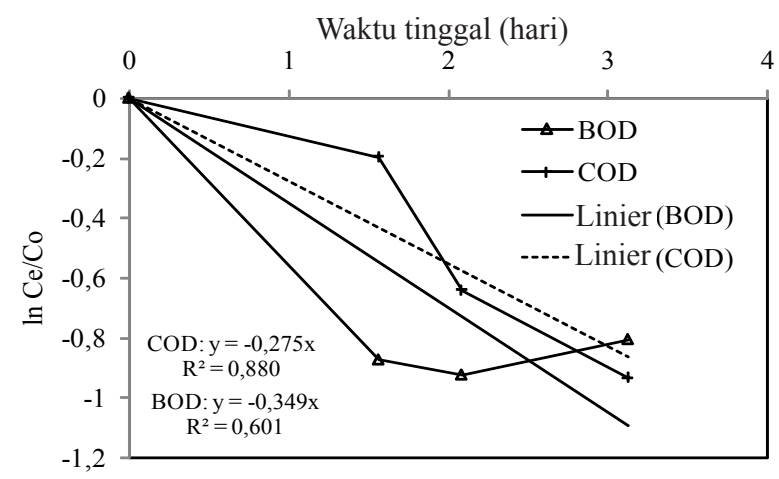

Gambar 4. Grafik linieritas kostanta pengurangan COD dan BOD

limbah domestik memiliki nilai $\mathrm{K}_{\mathrm{s}}$ untk COD sebesar 0,5609 lebih besar dari nilai $\mathrm{K}_{\mathrm{s}}$ utuk mengolah limbah cair industri penyamakan kulit hal tersebut kemungkinan disebabkan banyaknya jenis bahan kimia yang digunakan pada penyamakan kulit.

\section{KESIMPULAN}

Dari hasil penelitian dapat disimpulkan bahwa tanaman bambu air dapat digunakan sebagai tanaman untuk TTA dengan efektifitas penurunan COD mencapai $60,60 \%$ dengan waktu tinggal 3,125 hari, sedangkan penurunan BOD optimal sebesar $60,17 \%$ dicapai dengan waktu tinggal 2,083 hari. Pengurangan sulfida optimal dicapai dengan waktu tingal 1,563 hari sebesar $86,67 \%$ sedangkan untuk TSS penurunan optimal dapat dicapai dengan waktu tinggal 3,125 hari sebesar 94,64\%. Untuk logam krom pengurangan optimal terjadi pada waktu tinggal 2,083 hari sebesar 96,89\%. Konstanta laju penurunan COD sebesar 0,275/hari.

\section{UCAPAN TERIMA KASIH}

Ucapan terima kasih kami tujukan kepada Bapak Kepala Balai Besar Kulit, Karet, dan Plastik, atas arahan-arahan dalam pelaksanaan penelitian ini, Kepala Bidang Sarana Riset dan Standardisasi atas ijin untuk penggunaan fasilitas laboratorium, dan semua anggota kelompok kerja 1866.01.003 yang telah membantu kami dalam pelaksanaan penelitian.

\section{DAFTAR PUSTAKA}

Afrous, A., Hedayat, N., Liaghat, A., Mohammadpour, M., and Manshouri, M., 2010. Accumulation and uptake of nitrogen and $\mathrm{P}$ by four species of aquatic plants under arid and semi-arid conditions of Dezful, Iran, World Applied Sciences Journal, 10(8): 886-891.

Ahmad, M. H., 2009. Municipal wastewater treatment using constructed wetland: Removal of chemical oxygen demand (COD) and total suspended solid (TSS), Dissertation, Universiti Malaysia.

Borkar, R. P. and Mahatme, P. S., 2011. Waste water treatment with vertical flow constructed wetland, Internasional Journal of Environmental Sciences, 2(2): 590-603.

Calheiros, C. S., Rangel, A. O., and Castro, P. M., 2007. Constructed wetland systems vegetated with different plants applied to the treatment of tannery wastewater, Water Research, 41(8): 1790-1798.

Calheiros, C. S., Rangel, A. O., and Castro, P. M., 2009. Treatment of industrial wastewater with two-stage constructed wetlands planted with Typha latifolia and Phragmites australis, Bioresource Technology, 100(13): 3205-3213.

Chong, H. L. H., Ahmad. M. N., and Lim. P. E., 2009. Growth of Typha angustifolia and media biofilm formation in constructed wetland with defferent media, Borneo Science, 25(1): 11-21.

Debing. J., Baoqing. S., Hong. Z., and Jianming, H., 2010. Chemical oxygen demand, nitrogen and phosphorus removal by subsurface wetdlands with Phragmites vegetation in defferent model, Engineering Life Science, 10(10): 177-183

Karunaratne. S., Wijesiri B. S., and Sooriya, J. V. M., 2011. Estimation of reaction rate constant of pollutan removal for subsurface flow constructed wetland treating grey water, Society for Social Management Systems 2011, Colombo.

Lee, C. G., Fletcher, T. D., and Sun, G., 2009. Nitrogen removal in constructed wetland systems. Engineering in Life Sciences, 9(1): 11-22.

Sarafraz, S., Mohammad, T. A., Noor, M. J. M. M., and Liaghat, A., 2009. Wastewater treatment using horizontal subsurface flow constructed wetland, American Journal of Environmental Sciences, 5(1): 99-2009. 
Shreesadh, E. C., Thakur, S., and Chauhan, M. S., 2013. Treatment of RO reject for tannery industry - A technical review, Journal of Environmental Science and Sustainability (JESS), 1(4): 113-116.

USEPA, 1998. Design manual constructed wetland and aquatic plant system for municipal wastewater treatment, USEPA, USA.
Vymazal, J. and Kröpfelová, L., 2009. Removal of organics in constructed wetlands with horizontal sub-surface flow: A review of the field experience, Science of the Total Environment, 407(13): 3911-3922.

Yalcuk, A. and Ugurlu, A., 2009. Comparison of horizontal and vertical constructed wetland systems for landfill leachate treatment, BioresourceTechnology, 100(9):2521-2526. 